\title{
Long non-coding RNAs regulation of therapeutic resistance
}

\author{
Susan Tsang ${ }^{1,2}$, Tajhal Patel ${ }^{2}$, Jason T. Yustein ${ }^{1,2}$ \\ IIntegrative Molecular and Biomedical Sciences Program, Baylor College of Medicine, Houston, TX 77030, USA. \\ 2Department of Pediatrics, Texas Children's Cancer Center, Baylor College of Medicine, Houston, TX 77030, USA.
}

Correspondence to: Dr. Jason T. Yustein, Department of Pediatrics, Texas Children's Cancer Center, 1102 Bates St., C1025.07, Houston, TX 77030, USA. E-mail: yustein@bcm.edu

How to cite this article: Tsang S, Patel T, Yustein JT. Long non-coding RNAs regulation of therapeutic resistance. Cancer Drug Resist2019;2:550-67. http://dx.doi.org/10.20517/cdr.2019.58

Received: 8 Jul 2019 First Decision: 26 Jul 2019 Revised: 13 Aug 2019 Accepted: 28 Aug 2019 Published: 19 Sep 2019

Science Editor: Francois-Xavier Claret Copy Editor: Cai-Hong Wang Production Editor: Jing Yu

\begin{abstract}
Non-protein coding RNAs have emerged as a regulator of cell signaling and cancer progression through regulation of cell proliferation, metastatic burden, and cancer stem cell capacity. A subtype of non-protein coding RNA is long non-protein coding RNA (IncRNA). Besides their aforementioned roles in cancer cell biology, dysregulation of IncRNAs contribute to resistance to therapeutic treatments. A couple of important therapeutic classes are chemotherapy and targeted/hormone therapies. This review highlights the variety of malignancies affected by IncRNA dysregulation and the underlying mechanism causing therapeutic resistance.
\end{abstract}

Keywords: Long non-protein coding RNA, cancer, chemotherapeutic resistance, target therapeutics, hormone therapy, and microRNA sponge

\section{INTRODUCTION}

Cancer treatment has advanced a great deal over time with the introduction of targeted therapy, improved surgical procedures, precise radiotherapy, and continual development of chemotherapy. Cancer therapy discoveries first began in the 1940's, with the development of methotrexate ${ }^{[1,2]}$. Since then research has led to the production of more than a 100 chemotherapies and a variety of targeted therapeutics ${ }^{[3,4]}$. Some therapies like cisplatin, interferes with DNA repair while others like methotrexate acts as an inhibitor dihydrofolate reductas $\mathrm{e}^{[3,5]}$. However, even with the availability of multiple therapies, therapeutic resistance remains a major clinical problem. 
Cancer can attain drug resistance through acquired and intrinsic factors. Intrinsic factors consist of endogenous gene dyregulation, thus cancer cells are able to avoid cell toxicity when under cancer treatment. Acquired factors are activated after administration of drug treatment causing the remaining viable cells to develop a molecular perturbation which induces these cells to develop therapeutic resistance. Intrinsic and acquired factors attained within the tumor and/or in the tumor microenvironment can cause reduction in the cancer's sensitivity to therapeutics ${ }^{[6]}$.

Non-protein coding RNA (ncRNA) is a subclass of RNA previously considered as non-functional RNA based upon the idea that ncRNA lacks a cellular function ${ }^{[7]}$. However, in recent decades research has contradicted this idea by providing evidence of ncRNA differential expression in a variety of cell types and their ability to control a multitude of cellular function(s ()$^{[7]}$. The advent of RNA sequencing, has allowed for identification and additional characterization of ncRNAs which have led to subcategorization of ncRNAs into microRNA (miRNA), lncRNA, and circular RNA (circRNA) ${ }^{[8]}$.

LncRNAs are 200 or more base pairs in length ${ }^{[9,10]}$. A proportion of lncRNAs can present genomic features seen on mRNA such as a 5' cap and/or 3' poly (A) tail as well as share mRNA transcriptional regulation such as $\operatorname{lncRNAs}$ dependence on RNA polymerase $\mathrm{II}^{[10,11]}$. Cellular analysis of $\operatorname{lncRNAs}$ has provided insight on their ability to affect cellular function such as directly impacting protein translation through recruiting ribosomal subunits, and their role as a microRNA sponge ${ }^{[10]}$. In relation to cancer research, lncRNAs have been shown to be both pro-oncogenic and tumor suppressive. With their ability to directly regulate mechanisms involved in response to therapeutic agents. LncRNA expression can be tissuespecific making them an attractive target for therapeutic development since tissue-specific therapies will help minimize drug induced side effects ${ }^{[12]}$. This review will focus on the extensive evidence supporting lncRNAs regulatory role in therapeutic resistance across multiple cancer types [Table 1].

\section{CHEMOTHERAPY}

A mainstay treatment for a majority of malignancies is chemotherapy. Chemotherapy causes cancer cell toxicity by disrupting DNA replication, which can lead to cell death. There are several classes of chemotherapeutic agents: alkylating agents, platinum complexes, taxanes, tubulin interactive agents, topoisomerase II inhibitors, and anthracyclines ${ }^{[62]}$. While chemotherapy is the first-line treatment for a majority of cancers, resistance to chemotherapy is a major obstacle in cancer treatment. Common reasons for cancer resistance is the tumor cells are able to minimize their uptake of the drug and/or the enhance release of the drug from the cell at a rate where cell toxicity does not occur ${ }^{[63]}$.

Alkylating agents principal role is to control DNA synthesis in cells which are undergoing proliferation and in turn causing cytotoxicity. Alkylating agents can affect DNA synthesis by adding an alkyl group to guanine bases of DNA thus inhibiting double helix to properly form ${ }^{[64]}$. Glioblastoma is the leading cause of central nervous system brain tumor death in adults ${ }^{[65]}$. One of the first-line therapeutics to treat this disease is an alkylating agent, temozolomide (TMZ ${ }^{[6]}$. TMZ is an alkylating agent that can cause cell cycle arrest by adding a methyl group to purine bases of $\mathrm{DNA}^{[65]}$. Unfortunately there are inherent and acquired factors which prevent glioblastoma cells from being sensitive to TMZ.

There have been several lncRNAs that dysregulate glioblastoma's sensitivity to TMZ. One being lncRNATP73-AS1; clinical data has correlated elevated levels of TP73-AS1 to poor prognosis for glioblastoma patients. Analysis looking into glioblastoma cancer stem cells (gCSC) determined TP73-AS1 is higher in gCSC than compared to primary glioblastoma tissue. In addition knockdown of TP73-AS1 in gCSC suppresses cancer stem cell marker ALDH1 $\mathrm{A}_{1}{ }^{[52]}$. An inherent characteristic of gCSC is their ability to enhance tumor-driving therapy resistance, which is the reason why further studies were done to examine 
Table 1. IncRNAs with the capability of perturbing chemotherapeutic resistance

\begin{tabular}{|c|c|c|c|c|c|}
\hline IncRNA & $\begin{array}{l}\text { Level of IncRNA in } \\
\text { therapeutic resistant } \\
\text { state }\end{array}$ & Cancer & Therapeutic agent & Mechanism of action & Ref. \\
\hline ARSR & Upregulated & Liver & Doxorubicin & $\begin{array}{l}\text { Binding to PTEN mRNA causing degradation } \\
\text { of PTEN mRNA leading to enhancement of } \\
\text { PI3K/AKT }\end{array}$ & {$[13]$} \\
\hline ATB & Upregulated & Breast & Trastuzumab & $\begin{array}{l}\text { Binding to miR-200c modulates ZEB1 and } \\
\text { ZNF1 expression }\end{array}$ & {$[14]$} \\
\hline BCAR4 & Upregulated & Breast & Tamoxifen & $\begin{array}{l}\text { Phosphorylates ERBB2 and ERBB3 leading } \\
\text { to activation of AKT kinase } 1 / 2\end{array}$ & {$[15]$} \\
\hline CASC2 & Downregulated & Gastric & Cisplatin & $\begin{array}{l}\text { Sponging of miR-19a thus decreasing } \\
\text { apoptosis }\end{array}$ & {$[16]$} \\
\hline FAM84B-AS & Upregulated & Gastric & Cisplatin & $\begin{array}{l}\text { Preventing Bax translocation from } \\
\text { cytoplasm to mitochondria and keeping } \\
\text { cytochrome } \mathrm{C} \text { from releasing in } \\
\text { mitochondria thus reduction of apoptosis }\end{array}$ & {$[17]$} \\
\hline FOXC2-AS1 & Upregulated & Osteosarcoma & Doxorubicin & Acting on $A B C B 1$ & {$[18]$} \\
\hline FOXD2-AS1 & Upregulated & Bladder & Gemcitabine & $\begin{array}{l}\text { Sponging of miR-143 leading to upregulation } \\
\text { of } A B C C 3\end{array}$ & {$[19]$} \\
\hline GAS5 & Downregulated & Breast & Trastuzumab & Interacting with miR-21 increasing PTEN & {$[20]$} \\
\hline GBCDRInc1 & Upregulated & Gallbladder & Doxorubicin & $\begin{array}{l}\text { Interacting with PGK1 prevents PGK1 } \\
\text { ubiquination leads to subsequent } \\
\text { enhancement of ATG5-ATG12 }\end{array}$ & {$[21]$} \\
\hline \multirow[t]{2}{*}{ H19 } & Upregulated & Breast & Paclitaxel & Reducing p-AKT driving apoptotic pathway & {$[22]$} \\
\hline & Upregulated & Glioblastoma & Temozolomide & Activating Wnt/ $\beta$-Catenin pathway & {$[23]$} \\
\hline HANR & Upregulated & Liver & Doxorubicin & $\begin{array}{l}\text { Binding to GSKIP and decreasing } \mathrm{p}-\mathrm{GSK} 2 \beta \\
\text { thus reducing apoptosis }\end{array}$ & {$[24]$} \\
\hline HIF1A-AS2 & Upregulated & Bladder & Cisplatin & $\begin{array}{l}\text { Increasing HMG1 allows for increased } \\
\text { binding to p53, p63, and p73 which } \\
\text { decreases apoptosis }\end{array}$ & {$[25]$} \\
\hline \multirow[t]{3}{*}{ HOTAIR } & Upregulated & Breast & Tamoxifen & $\begin{array}{l}\text { Binding to ER and activating of GREB1, TFF1, } \\
\text { and c-Myc }\end{array}$ & {$[26]$} \\
\hline & Upregulated & Colorectal & Cisplatin & $\begin{array}{l}\text { Sponging of miR-203a-3p leads to activation } \\
\text { of } \beta \text {-Catenin/Wnt pathway }\end{array}$ & {$[27]$} \\
\hline & Upregulated & Lung & Crizotinib & $\begin{array}{l}\text { Inducing of ULK1 phosphorylation leading to } \\
\text { autophagy }\end{array}$ & {$[28]$} \\
\hline \multirow[t]{2}{*}{ HOXD-AS1 } & Upregulated & Glioblastoma & Cisplatin & $\begin{array}{l}\text { Interacting with miR-204 leading to } \\
\text { reduction of apoptosis genes caspase- } 3 \text { and } \\
\text { caspase } 9\end{array}$ & {$[29]$} \\
\hline & Upregulated & Prostate & Paclitaxel; Bicalutamide & $\begin{array}{l}\text { Binding to WDR5 causes activation of PLK1, } \\
\text { AURKA, FOXM1, CDC } 25 c \text {, UBE2C, CCNA2, } \\
\text { and CCNB1 }\end{array}$ & [30] \\
\hline LBCS & Downregulated & Bladder & $\begin{array}{l}\text { Cisplatin and } \\
\text { Gemcitabine }\end{array}$ & $\begin{array}{l}\text { Prevents binding to hnRNPK-EZH2 leading } \\
\text { to increase in SOX } 2 \text { thus reducing apoptosis }\end{array}$ & {$[31]$} \\
\hline LET & Downregulated & Bladder & Gemcitabine & $\begin{array}{l}\text { Increase in NF90 leading to suppressing } \\
\text { miR-145 }\end{array}$ & {$[32]$} \\
\hline LINC00460 & Upregulated & Lung & Gefitinib & Acting on miR-769-5p-EGFR axis & [33] \\
\hline Linc00518 & Upregulated & Prostate & Paclitaxel & $\begin{array}{l}\text { Binding to miR-216-5p leads to } \\
\text { enhancement of GATA6 }\end{array}$ & [34] \\
\hline LUCAT1 & Upregulated & Osteosarcoma & Methotrexate & $\begin{array}{l}\text { LUCAT1 } 3 \text { ' UTR region binds to } \mathrm{miR}-200 \mathrm{c} \\
\text { preventing competitive inhibition of miR- } \\
200 \text { c binding to ABCB1 }\end{array}$ & {$[35]$} \\
\hline MACC1 & Upregulated & Gastric & Oxaliplatin and 5-FU & $\begin{array}{l}\text { MACC1 level is dependent upon TGFB1 from } \\
\text { mesenchymal stem cells. MACC1 binds to } \\
\text { miR-145-5p }\end{array}$ & [36] \\
\hline MALAT1 & Upregulated & Colorectal & Oxaliplatin & $\begin{array}{l}\text { Binding to miR-218, leading to enhances } \\
\mathrm{EZH} 2 \text { and } \mathrm{E}-\mathrm{Cadherin}\end{array}$ & {$[37]$} \\
\hline MBNL1-AS1 & Downregulated & Lung & Gefitinib and Cisplatin & $\begin{array}{l}\text { Sponging miR-301b-3p, increasing the levels } \\
\text { of TGFBR2 to activated TGF- } \beta\end{array}$ & {$[38]$} \\
\hline MEG3 & Downregulated & Lung & Cisplatin & $\begin{array}{l}\text { Inactivating of p53 and } \mathrm{Bcl}-\mathrm{xl} \text {, preventing } \\
\text { mitochondrial apoptosis }\end{array}$ & [39] \\
\hline \multirow[t]{2}{*}{ NEAT1 } & Upregulated & Liver & Sorafenib & $\begin{array}{l}\text { Suppressing miR-335 causing a decrease in } \\
\text { c-MET }\end{array}$ & {$[40]$} \\
\hline & Upregulated & Osteosarcoma & Cisplatin & $\begin{array}{l}\text { Knockdown of miR-34-c causing a decrease } \\
\text { in cell cycle arrest }\end{array}$ & {$[41]$} \\
\hline
\end{tabular}




\begin{tabular}{|c|c|c|c|c|c|}
\hline & Upregulated & Prostate & Docetaxel & $\begin{array}{l}\text { Binding to miR-34a leads to enhancement } \\
\text { of RET }\end{array}$ & {$[42]$} \\
\hline OIP5-AS1 & Upregulated & Osteosarcoma & Cisplatin & $\begin{array}{l}\text { Decrease in miR-34-5p causes elevated } \\
\text { levels of LPAAT-B leading to inactivation of } \\
\text { PI3K/AKT/mTOR pathway }\end{array}$ & [43] \\
\hline \multirow[t]{2}{*}{ PVT-1 } & Upregulated & Colorectal & 5-FU; Cisplatin & $\begin{array}{l}\text { Regulating ABCB1, Bcl-2, and mTOR; } \\
\text { increase ABCB1, MDPR1 and Bcl-2 but } \\
\text { decreasing Bax and cleaved caspase } 3\end{array}$ & {$[44,45]$} \\
\hline & Upregulated & Gastric & $5-\mathrm{FU}$ & Increasing Bcl-2 & [46] \\
\hline SBF2 & Upregulated & Glioblastoma & Temozolomide & $\begin{array}{l}\text { Sponging miR-151a-3p causing reduction of } \\
\text { XRCC4 }\end{array}$ & [47] \\
\hline SNHG1 & Upregulated & Liver & Sorafenib & $\begin{array}{l}\text { miR-21 enhances SNHG1 causing nuclear } \\
\text { retention and upregulation of SLC3A2 and } \\
\text { enhancement of AKT pathway }\end{array}$ & [48] \\
\hline SNHG12 & Upregulated & Lung & $\begin{array}{l}\text { Cisplatin, Paclitaxel, } \\
\text { and Gefitinib }\end{array}$ & $\begin{array}{l}\text { Binding directly to miR-181-a causing an } \\
\text { increase in phosphorylated MAPK1 which } \\
\text { activates MAPK1, MAP2K1, and SLUG } \\
\text { pathway thus reducing apoptosis }\end{array}$ & [49] \\
\hline TATDN1 & Upregulated & Lung & Cisplatin & $\begin{array}{l}\text { Sponging miR-451 leading to enhancement } \\
\text { of TRIM } 66\end{array}$ & {$[50]$} \\
\hline THOR & Upregulated & Gastric & Cisplatin & $\begin{array}{l}\text { Binding to 3'UTR of SOX9 leading to SOX9 } \\
\text { mRNA stability }\end{array}$ & {$[51]$} \\
\hline TP73-AS1 & Upregulated & Glioblastoma & Temozolomide & Loss of ALDH1A1 & {$[52]$} \\
\hline \multirow[t]{2}{*}{ TUG1 } & Upregulated & Colorectal & Methotrexate & Interacting with miR-186 enhances CPEB2 & [53] \\
\hline & Upregulated & Liver & Adriamycin & Targeting ABCB1, PARP, and caspase-3 & [54] \\
\hline \multirow[t]{5}{*}{ UCA1 } & Upregulated & Bladder & Cisplatin & Upregulation of WNT6 pathway & [55] \\
\hline & Upregulated & Breast & Tamoxifen & Activating Wnt/ $\beta$-Catenin; p-AKT/mTOR & [56] \\
\hline & Upregulated & Colorectal & $5-\mathrm{FU}$ & $\begin{array}{l}\text { Sponging of miR-204-5p leading to } \\
\text { upregulation of } \mathrm{BCl}-2 \text {, RAB22A, and CREB1 }\end{array}$ & {$[57]$} \\
\hline & Upregulated & Lung & Gefitinib & Inducing AKT/mTOR pathway & {$[58]$} \\
\hline & Upregulated & Prostate & Docetaxel & Reducing miR-204 which increased SIRT1 & [59] \\
\hline XIST & Upregulated & Colorectal & Doxorubicin & $\begin{array}{l}\text { Binding to miR-124 leading to an increase in } \\
\text { SGK1 }\end{array}$ & {$[60]$} \\
\hline ZFAS1 & Upregulated & Gastric & $\begin{array}{l}\text { cis-platinum and } \\
\text { Paclitaxel }\end{array}$ & Enhancing Wnt/ $\beta$-catenin pathway & {$[61]$} \\
\hline
\end{tabular}

ARSR: Activated in RCC with sunitinib resistance; PTEN: phosphatase and tension homolog; PI3K: phosphoinositide 3-kinase; AKT: protein kinase 3; ATB: activated by TGF- $\beta$; ZEB1: Zinc finger E-Box binding homeobox 1; ZNF1: Zinc finger protein 1; BCAR4: breast cancer antiestrogen resistance 4; ERBB2: Erb-B2 receptor tyrosine kinase 2; ERBB3: Erb-B2 receptor tyrosine kinase 3; CASC2: cancer susceptibility candidate 2; Bax: Bcl-2 associated X; FOXC2-AS1: cancer susceptibility candidate 2; ABCB1: ATP bonding cassette subfamily B member 1; MDPR1: multi drug resistance protein 1; FOXD-AS1: FOXD2 adjacent opposite strand RNA 1; ABCC3: ATP binding cassette subfamily c member 3; GAS5: growth arrest-specific transcript 5; GBCDRInc1: gallbladder cancer drug resistance-associated IncRNA1; PGK1: phosphoglycerate kinase 1; HANR: HCC associated long non-coding RNA; GSKIP: glycogen synthase Kinase 3 interacting protein; GSK3 $\beta$ : glycogen synthase kinase $3 \beta$; HIF1A-AS2: hypoxia inducible factor 1 alpha-antisense RNA 2; HMG1: high mobility group Box 1; HOTAIR: HOX transcript antisense RNA; ER: estrogen receptor; GREB1: growth regulating estrogen receptor binding 1; TFF1: trefoil factor 1; ULK1: Unc-51 like autophagy activating kinase 1; HOXD-AS1: HOXD cluster antisense RNA 1; PKL1: kinesin-like protein Pk11; AURKA: Aurora kinase A; FOXM1: Forkhead Box M; CDC25c: cell division cycle 25c; UBE2C: ubiquitin conjugating enzyme E2 C; CCNA2: cyclin A2; CCNB1: cyclin B1; LBCS: low expressed in bladder cancer stem cells; hnRNPK: heterogeneous nuclear ribonucleoprotein K; EZH2: enzyme of zeste 2 polycomb repressor nuclear complex 2 subunit; SOX2: SRY-box2; LET: low expression in tumor; EGFR: epidermal growth factor receptor; GATA6: GATA binding protein 6; LUCAT1: lung cancer associated transcript 1; MACC1: metastasis associated in colon cancer-1; 5-FU: 5-fluorouracil; MALAT1: metastasis associated lung adenocarcinoma transcript 1; MBNL1-AS1: muscleblind-like 1 antisense RNA 1; TGFBR2: transforming growth factor beta receptor 2; TGF- $\beta$ : transforming growth factor beta; MEG3: maternally expressed 3; Bcl-XL: B-cell lymphoma-extra large; NEAT1: nuclear enriched abundant transcript 1; c-MET: MET proto-oncogene; RET: ret proto-oncogene; OIP5AS1: OIP5 antisense RNA 1; LPAAT-B: lysophosphatidic acid acyltransferase B; AKT: protein kinase 3; mTOR: mammalian TORC1; PVT-1: plasmacytoma variant transcript 1; Bcl-2: B-cell lymphoma 2; SBF2: SBF2 antisense RNA 1; XRCC4: X-ray repair cross complementing 4; SNHG1: small nucleolar RNA host gene 1; SLC3A2: solute carrier family 3 member 2; SNHG12: small nucleolar RNA host gene 12; MAPK1: mitogen-activated protein kinase 1; MAP2K1: mitogen-activated protein kinase kinase 1; SLUG: snail family transcriptional repressor 2; TATDN1: TatD DNase domain containing 1; TRIM66: tripartite motif containing 66; THOR: testis associated oncogenic; SOX9: SRY-Box 9; TP73-AS1: TP73 antisense RNA 1; ALDH1A1: aldehyde dehydrogenase 1 family member A1; TUG1: taurine upregulated gene 1; CPEB2: cytoplasmic polyadenylation element binding protein 2; PARP: poly ADP ribose polymerase; UCA1: urothelial cancer associated 1; WNT6: Wnt family member 6; RAB22A: RAB22A, Member RAS Oncogene Family; CREB1: CAMP responsive element binding protein 1; SPRK1: SRSF protein kinase 1; SIRT1: NAD-dependent deacetylase sirtuin-1; XIST: X-inactive specific transcript; SGK1: Serum/Glucocorticoid Regulated Kinase 1; ZFAS1: ZNFX1 Antisense RNA 1 
if knockdown of TP73-AS1 in gCSC will enhance gCSC sensitivity to TMZ. There hypothesis held true in that knockdown of TP73-AS1 elevated gCSC sensitivity to TMZ.

LncRNA-SBF2 antisense RNA1 (SBF2-AS1) is located within the exosome of glioblastoma tumor microenvironments and is another regulator of glioblastoma sensitivity to TMZ. SBF2-AS1 is seen to be upregulated in TMZ-resistant glioblastoma cells compared to parental cells. Functional studies found that knockdown of SBF2-AS1 in glioblastoma cells leads to diminished resistance to $\mathrm{TMZ}^{[47]}$. SBF2-AS1 exerts its ability to cause chemotherapeutic resistance by sponging miR-151a-3p causing a decrease in XRCC $4^{[47]}$. The reduction of XRCC4 is suppressive to tumor progression, because XRCC4 enhances double strand repair in glioblastoma ${ }^{[47]}$. Additionally, lncRNA-H19 is upregulated in TMZ-resistant cells. The knockdown of H19 in the TMZ-resistant cells enhances TMZ sensitivity through activating the Wnt/ $\beta$-Catenin pathway ${ }^{[23]}$.

Platinum based drugs are complexes consisting of neutral platinum (II) with amine ligands. Examples of platinum based drugs on the market are cisplatin, carboplatin, and oxaliplatin ${ }^{[66]}$. Cisplatin works as a platinum based chemotherapeutic drug by crosslinking the purine bases of DNA, which affects DNA repair thus drives apoptosis ${ }^{[3]}$. Platinum based agents are commonly combined with other cancer therapeutics to help circumvent therapeutic resistance ${ }^{[66]}$.

Cisplatin is a platinum-based chemotherapeutic drug used to treat NSCLC ${ }^{[6]}$. The high resistance of NSCLC to cisplatin has led to ongoing research focusing on how lncRNAs may enhance sensitivity of NSCLC to cisplatin. The lncRNA-TatD DNase domain containing 1 (TATDN1) has been shown to be upregulated in NSCLC tissue compared to normal tissue. TATDN1 is at higher levels in cisplatin-resistant NSCLC cells compared to cisplatin-sensitive NSCLC cells ${ }^{[50]}$. Chemosensitivity assays have demonstrated that knockdown of TATDN1 leads to an increase sensitivity of NSCLC cells to cisplatin. Molecular studies have shown that regulation of chemosensitivity is dependent upon TATDN1 binding to miR-451 which leads to enhancement of TRIM66, which has oncogenic properties ${ }^{[50]}$. A lncRNA-small nucleolar RNA host gene 12 (SNHG12) affects NSCLC sensitivity to a variety of therapeutic drugg ${ }^{[49]}$. SNHG12 is overexpressed in NSCLC compared to normal lung ${ }^{[49]}$. In addition, NSCLC cells resistant to cisplatin had higher levels of SNHG12 than non-resistant cells. To further elucidate SNHG12 role in therapeutic sensitivity, SNHG12 was knocked down in resistant cells then treated with cisplatin. The results showed that cells with SNHG12 knockdown had lower IC $_{50}$ values for cisplatin than the resistant cells. The regulatory axis causing SNHG12 role in drug resistance is through SNHG12 sponging miR-181-a, which causes an increase in phosphorylated MAPK1 which activates MAPK1, MAP2K1, and SLUG pathway, thus preventing apoptosis $^{[49]}$.

The most common subtype of NSCLC is lung adenocarcinoma ${ }^{[68]}$. As with other types of drugs used to treat NSCLC, cisplatin resistance is a major issue in treating lung adenocarcinoma ${ }^{[39]}$. Upon profiling, the lncRNA-MEG3 was identified to be downregulated in cisplatin-resistant cells. Further validation found that overexpressing MEG3 can help increase lung adenocarcinoma cells sensitivity to cisplatin. It was observed that loss of MEG3 leads to inactivation of $\mathrm{p} 53$ and $\mathrm{Bcl}-\mathrm{xL}$, thus preventing mitochondrial apoptosis $^{[39]}$.

While targeting lncRNAs within NSCLC would be beneficial in enhancing NSCLC sensitivity to therapeutic treatments, the targeting of lncRNAs specific to NSCLC cancer stem cells (CSC) would further increase the efficacy of these drugs. When comparing lncRNAs differentially expressed in NSCLC cells compared to NSCLC CSCs, Li et al. ${ }^{[38]}$ found lncRNA-MBNL1-AS1 had higher levels in NSCLC cells when compared to NSCLC CSCs ${ }^{[38]}$. Additional clinical support showed reduction of MBNL1-AS1 in NSCLC tissue of patients with lymph node metastasis $v s$. normal adjacent tissue and NSCLC tissue from patients without lymph node metastasis. Functional experiments determined that overexpression of MBNL1-AS1 can significantly 
reduce the $\mathrm{IC}_{50}$ of NSCLC CSC for cisplatin. It was recently reported that MBNL1-AS1 regulates therapeutic resistance in CSCs by competitive inhibition of miR-301b-3p. Downregulation of MBNL1-AS1 leads to enhanced levels of miR-301b-3p and higher levels of TGFBR2, which causes downstream activation of the TGF pathway thus reducing CSC phenotypes ${ }^{[38]}$.

The multi-modal treatment for muscle-invasive bladder cancer treatment consist of surgery, neoadjuvant chemotherapy-cisplatin, and adjuvant platinum-based chemotherapy ${ }^{[69]}$. The multimodal treatment for bladder cancer has lengthened the survival time but is highly ineffective at improving the overall survival rate due to therapeutic resistance ${ }^{[70]}$. To optimize treatment protocols, we must elucidate signaling pathways leading to resistance to therapeutics. LncRNA-UCA1 has been established in multiple cancers as oncogenic, including in bladder cancer ${ }^{[71,72]}$. Previous studies have identified UCA1 enhances epithelial to mesenchymal transition and invasion ${ }^{[7]}$. Additional functional results identified UCA1 ability to influence cisplatin resistance through upregulation of the Wnt pathway ${ }^{[55]}$.

As with other cancer types, bladder cancer is susceptible to molecular changes based upon oxygen intake and onset of hypoxia. It was found that hypoxic cells have an increase of hypoxia inducible factor 1 (HIF1), leading to elevated levels of lncRNA-hypoxia inducible factor $1 \alpha$-antisense (HIF1A-AS2), which enhances cisplatin resistance ${ }^{[25]}$. HIF1A-AS2 induces this phenotype by increasing HMGA1 which leads to enhanced binding to p53, p63, and p73 causing a decrease in BAX and an overall inhibition in apoptosis. This suggest that the HIF1A-AS2/HMGA1/p53 pathway may play an important role for therapeutic targeting in hypoxia-mediated therapeutic resistance in bladder cancer $^{[25]}$.

While the before mentioned lncRNAs were oncogenic, there are lncRNAs which possess tumor suppressor functions. LncRNA-low expressed in Bladder cancer stem cells (LBCS) was identified through stem cell profiling ${ }^{[31]}$. Survival analysis of bladder cancer patient data demonstrates that patients with lower quantities of LBCS exhibit poorer overall survival. In addition, LBCS is present at decreased levels in bladder cancer stem cells and cancer tissue ${ }^{[31]}$. Clinical data also shows a correlation of lower levels of LBCS to higher grades of bladder cancer ${ }^{[31]}$. Because chemotherapy resistance is a characteristic of cancer stem cells, it was important to understand LBCS sensitivity to cisplatin. Both in vivo and in vitro studies determined that overexpression of LBCS led to a decrease in bladder cancer resistance to cisplatin by elevating caspase $3 / 7$ and an increase in apoptosis. The increase in apoptosis is due to LBCS direct binding to hnRNPK and EZH2. This complex then reduces the level of SOX2 thus enhances $\mathrm{H} 2 \mathrm{~K}_{2} 2 \mathrm{me} 3^{[31]}$.

LncRNA-PVT-1 has also been assessed as a regulator of chemoresistance in colorectal cancer by impacting the sensitivity of colorectal cancer cells to cisplatin ${ }^{[45]}$. In cisplatin resistant cells, there is a higher level of PVT-1 compared to the control cells. Knockdown of PVT-1 in the resistant cells increases the cells sensitivity to cisplatin ${ }^{[45]}$. Ping et al ${ }^{[45]}$ noted that knockdown of PVT-1 can induce a decrease in multi drug resistance protein 1, ABCB1, and Bcl-2, while enhancement of apoptotic proteins Bax and cleaved caspase $3^{[45]}$. Another lncRNA seen to impact colorectal cancer cells sensitivity to cisplatin is lncRNA-HOTAIR. HOTAIR is shown to be upregulated in colorectal cancer tissue $v s$. normal adjacent tissue. In addition, the knockdown of HOTAIR helps increase colorectal cancer cells sensitivity to cisplatin. It is reported that HOTAIR regulates this phenotype by interaction with miR-203a-3p leading to the activation of $\beta$-Catenin/Wnt pathway $^{[27]}$.

Even with the use of surgery and chemotherapy, the overall survival of patients with advanced gastric cancer is approximately one year ${ }^{[46,73]}$. In advanced stages of gastric cancer, the chemotherapeutics commonly used are cisplatin, 5-FU, and oxaliplatin ${ }^{[7]}$. Because of the lack of effective therapeutics there is an urgent need for new treatment options. LncRNA-zinc finger antisense 1 (ZFAS1) has been shown to regulate gastric cancer cells sensitivity to cis-platinum ${ }^{[61]}$. ZFAS1 levels are higher in gastric cancer 
compared to para-carcinoma tissue. In addition, suppression of ZFAS1 in gastric cancer cells increases gastric cancer sensitivity to cis-platinum. ZFAS1 is able to regulate gastric cancer sensitivity by decreasing NKD2 and activating the Wnt/B-Catenin pathway ${ }^{[61]}$. LncRNA-FAM84B-AS has also been found to enhance cisplatin resistance in gastric cancer. FAM84B-AS is located on the antisense strand of FAM84B. While FAM84B acts a tumor suppressor, FAM84B-AS functions as an oncogene in gastric cancer ${ }^{[17,75]}$. FAM84B-AS is expressed at higher levels in gastric cancer cell lines and with progression of disease there is increase of FAM84B-AS level. To test FAM84B-AS role in gastric cancer sensitivity to cisplatin, a proliferation assay was performed and determined that the shRNA-FAM84B-AS gastric lines had higher rates of apoptosis than the parental cells. In addition, FAM84B-AS is able to reduce apoptosis by preventing Bax translocation from the cytoplasm to the mitochondrial membrane in turn keeping cytochrome $\mathrm{c}$ from releasing into the mitochondria ${ }^{[17]}$.

A tumor suppressive lncRNA, lncRNA-CASC2 was shown to be at lower levels in gastric cancer compared to normal adjacent tissue with additional finding that cisplatin-resistant gastric cells, BGC823 and SGC7901, have decreased levels of CASC2 compared to non-resistant cells. Kaplan-Meier survival analysis also showed a significant correlation between patients with low levels of CASC2 with poor prognosis ${ }^{[16]}$. To further confirm CASC2 role in chemosensitivity, cisplatin-resistant cells were transfected with CASC2 and subsequently decrease the $\mathrm{IC}_{50}$ of the cisplatin-resistant cells. The mechanism by which CASC2 is able to enhance resistance is through sponging of miR-19a thus decreasing apoptosis ${ }^{[16]}$. LncRNA-THOR is another regulator of cisplatin sensitivity for gastric cancer cells. THOR levels are higher in gastric cancer tissue in comparison to normal adjacent tissue. Functional analysis determined that knockdown of THOR in gastric lines suppresses both cancer stemness markers and phenotypes, in addition to decreasing gastric cancer cells sensitivity to cisplatin. SOX9 was a marker seen to have the largest decrease in expression when gastric cancer cells have knockdown of THOR. Mechanistically, THOR binding to the 3' UTR region of SOX9 leads to SOX9 mRNA stability causing increase in stemness phenotypes and cisplatin resistance ${ }^{[51]}$.

In osteosarcoma, lncRNA-NEAT1 is a regulator of cisplatin sensitivity. With data showing NEAT1 is overexpressed in osteosarcoma tissue in comparison to non-malignant tissues. NEAT1 causes its tumorigenic effect by enhancing osteosarcoma cell viability when treated with cisplatin. Results of both in vivo and in vitro studies, found that when both NEAT1 knockdown and parental cells are treated with cisplatin, the NEAT1 knockdown line had enhanced apoptosis. It was reported that NEAT1 promotes chemotherapeutic resistance in osteosarcoma by reducing the level of miR-34c and causing a decrease in cell cycle arrest via enhanced Bcl-2 and cyclin D1 expression ${ }^{[41]}$. LncRNA-OIP5-AS1 is also an oncogene that enhances chemotherapeutic resistance in osteosarcoma. OIP5-AS1 was overexpressed in cisplatinresistant osteosarcoma cells and the knockdown of OIP5-AS1 in these resistant cells led to an increase in osteosarcoma cell sensitivity to cisplatin. While it was shown that knockdown of OIP5-AS1 downregulated drug resistance genes, OIP5-AS1 reduction also enhanced the expression of miR-34-5p. Increased levels of miR-34-5p caused suppression of LPAAT- $\beta$ which leads to diminished PI3K/AKT/mTOR pathway $\operatorname{activity}^{[43]}$.

While in glioblastoma, lncRNA-HOXD-AS1 is a factor that impacts cisplatin induced cell toxicity ${ }^{[29]}$. HOXD-AS1 is upregulated in glioblastoma tissue. Kaplan-Meier survival analysis demonstrates that glioma patients with high HOXD-AS1 correlates with poor survival. One of the ways HOXD-AS1 is able to promote a low overall survival is by reducing glioblastoma sensitivity to cisplatin. Cisplatinresistant glioblastoma cancer cells have a significantly higher HOXD-AS1 level compared to parental cells. Molecular analysis identified HOXD-AS1 binding of miR-204 suppresses apoptotic genes: caspase-3 and caspase-9 leading to the lack in glioblastoma sensitivity to cisplatin ${ }^{[29]}$.

Oxaliplatin, is another platinum based $\mathrm{drug}^{[76]}$. The lncRNA-MALAT1 has been shown to be elevated in colorectal cancer tissue compared to normal tissue. In addition, advanced colorectal tumor stage positively 
correlates with MALAT1 expression. Furthermore, chemosensitivity studies demonstrated that the level of MALAT1 in colorectal cancer cells correlates to their resistance to oxaliplatin. MALAT1 is able to propagate this phenotype by sponging miR-218 leading to enhancement of EZH2 and E-Cadherin ${ }^{[37]}$.

The presence of mesenchymal stem cells (MSC) in the heterogeneous cellular structure of a tumor is a factor that enhances multi-drug resistance in gastric cancer ${ }^{[77,78]}$. The work of He et al ${ }^{[36]}$ determined how MSC enhancement of a lncRNA can regulate gastric cancer sensitivity to chemotherapeutic agents. Their study found gastric cancer cells incubated with MSCs led to a reduction in gastric cancer cells sensitivity to oxaliplatin and enhanced stemness phenotypes ${ }^{[36]}$. Based on previous research correlating fatty acid oxidation (FAO) to stemness and chemosensitivity, the investigation focused on gastric cancer cells requires FAO induction to allow for an increase in chemoresistance ${ }^{[79]}$. They identified that gastric cancer cells in the presence of MSCs led to an enhancement of FAO-associated enzymes and an increase in lncRNA-metastasis-associated in colon cancer-1 (MACC1) to promote chemoresistance and stemness. The upregulation of MACC 1 in gastric cancer cells was dependent upon secretion of TGF $\beta 1$ from MSC. MACC1 subsequently binds to miR-145-5p which then enhances carnitine palmitoyltransferase 1 to induce chemoresistance and stemness behavior in gastric cancer cells ${ }^{[36]}$.

Taxane class of anticancer agents alters the metaphase to anaphase transition by disrupting spindle microtubule formation, thus leading to cell death. Previous literature has cited that taxane resistance can occur in tumors which contain $\alpha$ and B-tubulin which polymerize into mitrotubules preventing the cell death induced by taxanes ${ }^{[80]}$.

Triple Negative Breast Cancer (TNBC)/basal-like sub-type makes up 15\%-20\% of all breast cancer diagnose $^{[81]}$. Unlike ER+ and HER2+ breast cancer, TNBC's are primarily treated with chemotherapy ${ }^{[81]}$. The first-line taxane based chemotherapeutic agent used to treat TNBC patients is paclitaxel. Paclitaxel functions by binding $\beta$-tubulin which causes microtubule stabilization and apoptotic cell death ${ }^{[82]}$. The lncRNA-H19 has been shown to be elevated in TNBC paclitaxel-resistant lines compared to parental cells. H19 is a lncRNA highly expressed during embryonic development but decreases after birth, specifically in mammary tissue ${ }^{[83]}$. Knockdown of $\mathrm{H} 19$ in paclitaxel resistant TNBC cell lines increases sensitivity to paclitaxel by reducing p-AKT (Ser473) driving the apoptotic pathway by decreasing Bcl-2 and enhancing cleaved caspase-3 and Bax expression ${ }^{[2]}$.

LncRNA-SNHG12 not only regulates NSCLC resistance to cisplatin but also to paclitaxel. NSCLC cells resistant to paclitaxel have higher levels of SNHG12 than non-resistant cells and knockdown of SNHG12 in paclitaxel-resistant lines causes a suppression of paclitaxel resistance. SNHG12 decreases sensitivity through the binding of miR-181-a leading to phosphorylation of MAPK1 thus a reduction in apoptosis ${ }^{[49]}$.

In gastric cancer, lncRNA-ZFAS1 regulates gastric cancer sensitivity to paclitaxel ${ }^{[6]}$. Gastric carcinoma cells have elevated levels of ZFAS1 compared to gastric paracarcinoma cells. The knockdown of ZFAS1 causes increase in gastric cancer sensitivity to paclitaxel by suppressing the NKD2 leading to induction of Wnt negative regulator, thus leading to the induction of Wnt/B-Catenin pathway ${ }^{[6]]}$.

Castration resistant prostate cancer is treated with several taxane-based therapeutics ${ }^{[84]}$. He et al. ${ }^{[34]}$ identified Linc00518 as elevated in prostate cancer compared to non-malignant models. In addition, paclitaxel-resistant DU145 and PC3 cells have increased levels of Linc00518 compared to non-resistant cells. With the use of siLinc00518, they determined that knockdown of Linc00518 causes increase sensitivity of prostate cancer cells DU145 and PC3 to paclitaxel. With the help of bioinformatic tools, it was predicted and then confirmed that Linc00518 binds to miR-216b-5p. Additional studies identified Linco0518-miR$216 \mathrm{~b}-5 \mathrm{p}$ binding leads to enhancement of GATA $6^{[34]}$. Another lncRNA which plays a role in sensitivity 
to paclitaxel is lncRNA-HOXD-AS1. It was seen that prostate cancer tissues from patients with higher grade prostate cancer have elevated levels of HOXD-AS1 compared to tissue from lower tumor grades. By knocking down HOXD-AS1, there is an increase prostate cancer cell sensitivity to paclitaxel. The mechanism which by HOXD-AS1 is able to regulate the sensitivity of prostate cancer cells to paclitaxel is by HOXD-AS1 binding to WDR5 leading to activation of proteins PLK1, AURKA, FOXM1, CDC25c, $\mathrm{UBE} 2 \mathrm{C}, \mathrm{CCNA} 2$, and $\mathrm{CCNB} 1$ which are critical proteins in the mitosis, cell cycle regulation, microtubule stabilization, and androgen receptor signaling pathways ${ }^{[30]}$.

LncRNA-NEAT1 is a critical component of the nuclear paraspeckle structure and is elevated levels in prostate cancer tissue and has the ability to enhance tumorigenic behaviors which includes decreasing tumor sensitivity to taxane based chemotherapeutic agent docetaxel ${ }^{[85,86]}$. NEAT1 was significantly elevated in docetaxel-resistant prostate cancer cell lines compared to docetaxel-sensitive lines. The knockdown of NEAT1 in the resistant lines caused these cells to have a decrease in their $\mathrm{IC}_{50}$ value for docetaxel. In addition, it was found that NEAT1 causes decrease in sensitivity by binding to miR-34a, thus resulting in the increase in RET which encodes an oncogenic receptor tyrosine kinase ${ }^{[42]}$.

Doxorubicin is a chemotherapeutic agent used to treat both adult and pediatric cancer. Cell toxicity caused by doxorubicin is through intercalation of DNA and inhibition of topoisomerase II-mediated DNA repair. Doxorubicin resistance has been reported through the activation of resistance-mediated genes such as $\mathrm{ABCB} 1, \mathrm{ABCC} 1$, and TOP2 $\mathrm{A}^{[87]}$.

Gallbladder cancer is the fifth most-prevalent digestive malignancy and one reason for poor survival is late detection of malignancy ${ }^{[88]}$. Unfortunately, chemotherapy treatment is highly ineffective for patients with gallbladder cancer, which strongly contributes to the 5 -year survival for gallbladder cancer being less than $10 \%$. The lack in effective treatment causes a critical need for molecular research to further understand the genetic factors preventing chemotherapeutic efficacy ${ }^{[89]}$. Cai et al ${ }^{[21]}$ investigated this issue by studying the role of lncRNA-GBCDRlnc1. GBCDRlnc1 was identified through profiling the differential level of lncRNAs in doxorubicin-resistant gallbladder cell lines $v s$. doxorubicin-sensitive lines. Verification of their profiling found that GBCDRlnc1 is expressed at higher levels in gallbladder cancer tissue than adjacent normal tissue. Their research determined that knockdown of GBCDRlnc1 in gallbladder cells causes an increase in sensitivity to doxorubicin. GBCDRlnc1 promotes this tumorigenic function by interacting with phosphoglycerate kinase 1 (PGK1) and preventing its ubiquitin-mediated degradation and subsequent enhancement of autophagy regulator ATG5-ATG12 conjugate, an enhancer of chemoresistance ${ }^{[21,90]}$.

Doxorubicin is also used in the treatment of colorectal cancer. Zhu et al. ${ }^{[60]}$ found that doxorubicinresistant colorectal models have an elevated level of lncRNA-XIST compared to the parental cells. Further evaluation determined knockdown of XIST leads to lessening of doxorubicin resistance in colorectal cells. XIST is able to enhance this behavior by binding to miR-124 leading to the enhancement of Serum-and Glucocorticoid-induced Kinase $(\mathrm{SGK} 1)^{[60]}$. SGK1 is a serine/threonine protein kinase, specifically apart of protein kinase A, G, and C family ${ }^{[9]}$. Previous reports have shown SGK1 is elevated in colorectal tumor and enhances tumorigenic behaviors ${ }^{[60]}$.

Adriamycin (doxorubicin) is a chemotherapeutic agent used to treat hepatocellular carcinoma. While chemotherapy is the first-line treatment for hepatocellular carcinoma, there is the possibility of chemotherapeutic resistance ${ }^{[92]}$. Yang et al ${ }^{[54]}$ profiled the differential expression of lncRNAs in adriamycinresistant hepatocellular carcinoma to non-resistant hepatocellular carcinoma cells. From their analysis, they determined lncRNA-TUG1 was upregulated in the resistant cells unlike the non-resistant cells. Subsequently, they found siRNA knockdown of TUG1 in adriamyacin-resistant cells restored sensitivity to this chemotherapy. Their mechanistic studies found that TUG1 is able to enhance resistance through 
targeting the apoptotic pathway, specifically ABCB1, PARP, and caspase $3^{[54]}$. In addition, clinical data found earlier stages of hepatocellular carcinoma have lower levels of lncRNA-HANR compared to later stages, and suppressing HANR expression can enhance hepatocellular carcinoma sensitivity to doxorubicin. Mechanistically HANR binds to GSKIP, which reduces p-GSK $2 \beta$ thus reducing apoptosis ${ }^{[24]}$. LncRNAARSR also plays are role in hepatocellular carcinoma sensitivity to doxorubicin. ARSR is overexpressed in doxorubicin-resistant hepatocellular carcinoma cells. Both in vivo and in vitro studies using doxorubicinresistant cells with knockdown of ARSR showed an increase in hepatocellular carcinoma cells sensitivity to doxorubicin. ARSR is able to regulate doxorubicin sensitivity by binding and leading to degradation of PTEN mRNA and subsequent activation of PI3K/AKT pathway ${ }^{[13]}$.

One lncRNA recently found to be a regulator of doxorubicin sensitivity in osteosarcoma is lncRNAFOXC2-AS1. FOXC2-AS1 is an antisense lncRNA found to be transcribed from the negative strand of the forkhead box protein $\mathrm{C}_{2}{ }^{[93]}$. FOXC2-AS1 is upregulated in osteosarcoma cell lines and tissue. In addition, doxorubicin-resistant osteosarcoma cells have higher levels of FOXC2-AS1 compared to doxorubicinsensitive cells. In both in vivo and in vitro studies, it was seen that siFOXC2-AS1 enhances osteosarcoma cell line sensitivity to doxorubicin. FOXC2-AS1 facilitates doxorubicin sensitivity by increasing, the drug resistance gene, $\mathrm{ABCB}{ }^{[18]}$.

Another chemotherapeutic drug is gemcitabine ${ }^{[94]}$. Gemcitabine inhibits DNA synthesis by addition of the nucleotide analog during the elongation phase, which halts proofreading and causes cell death ${ }^{[94]}$. It has been shown that patients with a higher level of lncRNA-FOXD2-AS1 has gemcitabine resistant bladder cancer. In addition, confirmatory data showed that upregulating FOXD2-AS1 enhances cancer cells resistance to gemcitabine and thus allowing for continual tumor growth ${ }^{[19]}$. The regulatory pathway of FOXD2-AS1 is through interaction of miR-143, thus preventing the competitive binding of miR-143 and $\mathrm{ABCC}^{\left[{ }^{[19]}\right.}$. The upstream interaction between miR-143 and FOXD2-AS1 causes an enhancement of ABCC3 in bladder cancer correlates with previous reports of ABCC3 being elevated in bladder cancer tissue. In addition, these reports showed overexpression of $\mathrm{ABCC} 3$ causes increase in proliferation and drug resistance ${ }^{[95]}$.

Another lncRNA examined in bladder cancer stem cells is lncRNA-LET. LET is a downstream target of TGFB1 and has been shown to be downregulated in bladder cancer cells ${ }^{[32]}$. Those cells with low expression of LET exhibit chemoresistence to gemcitabine through the regulation of NF9o/miR-145 axis ${ }^{[32]}$. The perturbation of this axis through LET enhancement could potentially reverse the chemotherapeutic resistance effect caused by TGF $\beta 1$.

5-Flurouracil (5-FU) is the third most common chemotherapeutic agent used for the treatment of cancer ${ }^{[96]}$. 5-FU works by being catabolized by dihydropyrimidine dehydrogenase leading to the end product of fluorodeoxyuridine monophosphate (FdUMP). FdUMP binds to thymidylate synthase and 5,10 methylene tetrahydrofolate causing a toxic effect by inhibiting DNA synthesis and transcription ${ }^{[97]}$.

Gastric cancer responds to 5 -FU in about $30 \%$ of cases ${ }^{[98]}$. Du's group found patients with late-stage gastric cancer have elevated levels of lncRNA-PVT-1, which coincides with previous studies showing PVT-1's ability to regulate 5-FU sensitivity ${ }^{[46]}$. Chemosensitivity studies were performed to see if elevated levels of PVT-1 can increase gastric cells resistance to 5-FU. The data from this study showed overexpression of PVT-1 can suppress gastric cancer cells sensitivity to 5-FU by increasing Bcl-2 leading to an anti-apoptotic effect $^{[46]}$. LncRNA-MACC1 previously mentioned as a regulator of gastric cancer sensitivity to cisplatin also regulates 5-FU sensitivity through upregulation of MACC1 by MSC ${ }^{[36]}$.

In colorectal cancer, the elevated level of PVT-1 causes inhibition of colorectal cancer cells sensitivity to 5-FU. Fan et al ${ }^{[44]}$ determined PVT-1 regulates of ABCB1 and Bcl-2 level in addition to overexpression of 
PVT-1 in resistant cells leads to upregulation of $\mathrm{mTOR}^{[44]}$.

Sorafenib is chemotherapeutic agent which inhibits cancer by inhibiting several tyrosine kinases including VEGFR1, c-Kit, and different isoforms of Raf kinase ${ }^{[99]}$. While clinical data showed promising anti-tumor response in patients treated with sorafenib, the survival rate of carcinoma patients has not drastically increased since approval of sorafenib ${ }^{[4]}$. A reason for the lack in efficacy is due to carcinoma resistance to sorafenib ${ }^{[4]}$. LncRNAs have been identified as regulators of sorafenib sensitivity. Recent work by the Guo lab identified lncRNA-NEAT1 upregulation in hepatocellular carcinoma tissues compared to normal adjacent tissue $^{[100]}$. Further analysis of NEAT1 demonstrated that NEAT1 knockdown increases hepatocellular carcinoma cells sensitivity to sorafenib. Mechanistically, this is the result of NEAT1 sponging miR-335 suppressing c-MET and AKT pathway thereby reducing apoptosis ${ }^{[40]}$. LncRNA-small nucleolar RNA host gene 1 (SNHG1) is upregulated in sorafenib-resistant hepatocellular carcinoma cells compared to parental lines. In hepatocellular carcinoma, sorafenib resistance is caused by miR-21 enhancement of SNHG1 which leads to SNHG1 retention in the nucleus and enhances transcription of SLC3A2 and activation of the AKT pathway $^{[48]}$.

\section{TARGETED THERAPY}

Targeted therapy aims to deliver drugs specific to intracellular molecular perturbations or alteration within the tumor microenvironment. The purpose is to reduce the off-target effects which develop when treating cancer patients with other types of therapeutics. As with other cancer therapies, therapeutic resistance is an obstacle when treating patients with targeted agents ${ }^{[101]}$.

Non-small cell lung cancer (NSCLC) accounts for approximately 85\% of lung cancer cases, with a 5-year survival of about $15 \%{ }^{[102]}$. An agent used to treat NSCLC is gefitinib, which inhibits the tyrosine kinase activity of the epidermal growth factor receptor ${ }^{[103]}$. Initially gefitinib provides a measureable response for many NSCLC patients however within one year approximately $50 \%$ of patients develop resistance ${ }^{[33]}$. Reports show perturbation of lncRNAs diminish NSCLC sensitivity to gefitinib ${ }^{[33,49]}$. Ma et al ${ }^{[33]}$ reports that gefitinib-resistant NSCLC cells have elevated levels of lncRNA-LINC00460 compared to non-resistant cells. To confirm their prediction of LINC00460 role in gefitinib resistance, they transiently knocked down LINC00460 in gefitinib-resistant cells and saw an increase sensitivity to gefitinib. This group also identified that LINC00460 regulates this action by 3'UTR of LINC00460 sponging miR-769-5p, thus enhancing EGFR protein $_{\text {expression }}^{[33]}$.

Besides its ability to contribute to resistance to cisplatin and paclitaxel, lncRNA-SNHG12 is also able to contribute to NSCLC resistance to gefitinib. The knockdown of SNHG12 enhances NSCLC cells sensitivity to gefitinib through the previously mentioned miR-181/MAPK1 axis $^{[49]}$. Gefitinib resistance is also present in NSCLC CSCs. NSCLC CSCs have lower levels of IncRNA- MBNL1-AS1 compared to NSCLC cells which diminishes binding to mir-301-3b and subsequent enhancement of the TGF pathway. When MBNL1-AS1 levels are increased in NSCLC CSCs, there was a noted reduction in gefitinib resistance ${ }^{[38]}$.

Human epidermal growth factor receptor 2 (HER2+) breast cancer is the second most lethal subtype of breast cancer ${ }^{[14]}$. Trastuzumab, the first-line targeted therapeutic for HER2+ patients, targets the extracellular domain of the HER2 receptor to inhibit its function ${ }^{[104,105]}$. Although trastuzumab treatment has helped in increasing the survival of HER2+ patients, it only has an approximately $35 \%$ success rate $^{[106]}$. Studies have shown that resistance to trastuzumab can result from HER2 gene amplification and activation of PI3K. These molecular perturbations are not detected by trastuzumab thus leading to resistance ${ }^{[107]}$. Trastuzumab's low rate of success suggest a critical need to identify underlying mechanisms that enhance trastuzumab effectiveness. The Shi lab determined that HER2+ SKBR-3 parental cell line had 
differential lncRNA-ATB expression compared to SKBR-3 trastuzumab-resistant cells (SKBR-3/TR). ATB was upregulated in the SKBR-3/TR compared to the parental line. Furthermore, knockdown of ATB in SKBR-3/TR line increased the cells sensitivity to trastuzumab. ATB binds to mir-200c thereby modulating ZEB1 and ZNF1 expression and contributing to enhanced trastuzumab resistance ${ }^{[14]}$. Unlike ATB, another lncRNA, lncRNA-GAS5 has been shown to be downregulated in trastuzumab-resistant cell lines and low levels of GAS5 is associated with poor prognosis. It was reported that a dual inhibitor for both ErbB1 and ErbB2 increased expression of GAS5 causing a reversal of GAS5 ability to regulate trastuzumab sensitivity in HER2+ lines. Mechanistically, GAS5 is able to regulate HER2+ cells sensitivity by binding to miR-21and increasing PTEN expression ${ }^{[20]}$.

A therapeutic drug used to treat late-stage NSCLC is crizotinib ${ }^{[108]}$. Crizotinib is an inhibitor of receptor tyrosine kinase anaplastic lymphoma kinase (ALK) and c-Met. Cells that are positive for ALK and c-Met should be highly susceptible to crizotinib leading to apoptosis ${ }^{[108,109]}$. Unfortunately a subset of NSCLC patients become highly resistant to crizotinib after several rounds of treatment ${ }^{[108]}$. Yang et al ${ }^{[28]}$ identified a lncRNA-HOTAIR is overexpressed in NSCLC patients and that knockdown of HOTAIR can decrease NSCLC cells resistance to crizotinib ${ }^{[28]}$. HOTAIR is able to accomplish this phenotype by activation of ULK1 phosphorylation leading to autophagy ${ }^{[28]}$.

Methotrexate is an inhibitor of dihydrofolate reductase enzyme, an enzyme critical for DNA synthesis and cell growth ${ }^{[5]}$. Methotrexate is a targeted therapeutic agent which cancer patients can develop resistance too. The lncRNA-TUG1 is expressed at higher levels in methotrexate-resistant colorectal cancer cells when compared to non-resistant cells. Additional evidence shows that transient knockdown of TUG1 causes increased sensitivity to methotrexate in colorectal cancer cells. TUG-1 promotes chemoresistance by sponging to miR-186, which causes enhancement of, oncogene, $\mathrm{CPEB} 2{ }^{[53]}$.

LncRNA-LUCAT1 is seen to be upregulated in methotrexate-resistant osteosarcoma cells compared to methotrexate-sensitive cells. The transient knockdown of LUCAT1 caused an increase in methotrexate sensitivity and also a decrease in the protein level of drug resistance related genes (ABCB1, MRP5, and MVP). Mechanistically, LUCAT1 is able to enhance chemoresistance through LUCAT1 3' UTR region sponging miR-200c and increasing the expression of $\mathrm{ABCB} 1$, which is a known miR-200c target ${ }^{[35]}$.

\section{HORMONE THERAPY}

Hormone therapy is commonly used to treat both breast and prostate cancer. For breast and prostate cancer, the malignancy is dependent upon the level of steroid hormone receptors. Factors contributing to hormone therapy resistance are pre-receptor level, perturbation of hormone and receptor level, and/or postreceptor level ${ }^{[10]}$.

Approximately $70 \%$ of breast cancer patients have luminal A/estrogen receptor-positive (ER+) breast cancer which consists of low proliferation rate genes such as Ki67 and low levels of HER $2^{[111,112]}$. Tamoxifen is a common hormone therapy used to treat ER+ patients. Tamoxifen is a non-steroidal anti-estrogen that competitively binds to estrogen receptor which then causes tamoxifen resistance. While tamoxifen treatment has reduced relapse by $47 \%$, there is still a high majority of patients who inevitable have reoccurrence of their breast cancer ${ }^{[113]}$. Recent reports have shown breast cancer cells with elevated levels of certain lncRNAs are less responsive to tamoxifen. Tamoxifen acts by binding directly to the estrogen receptor (ER), thereby preventing the proliferative effect caused by estrogen binding to the receptor ${ }^{[114]}$. Godinho et al. ${ }^{[15]}$ found ER+ breast cancer cells have elevated levels of lncRNA-BCAR4 ${ }^{[115]}$. In addition, BCAR4 induction in estrogen dependent breast cancer cell line, ZR-75-1, led to an increase resistance to tamoxifen therapy ${ }^{[15]}$. It has been found that BCAR4 contributes to tamoxifen resistance through 


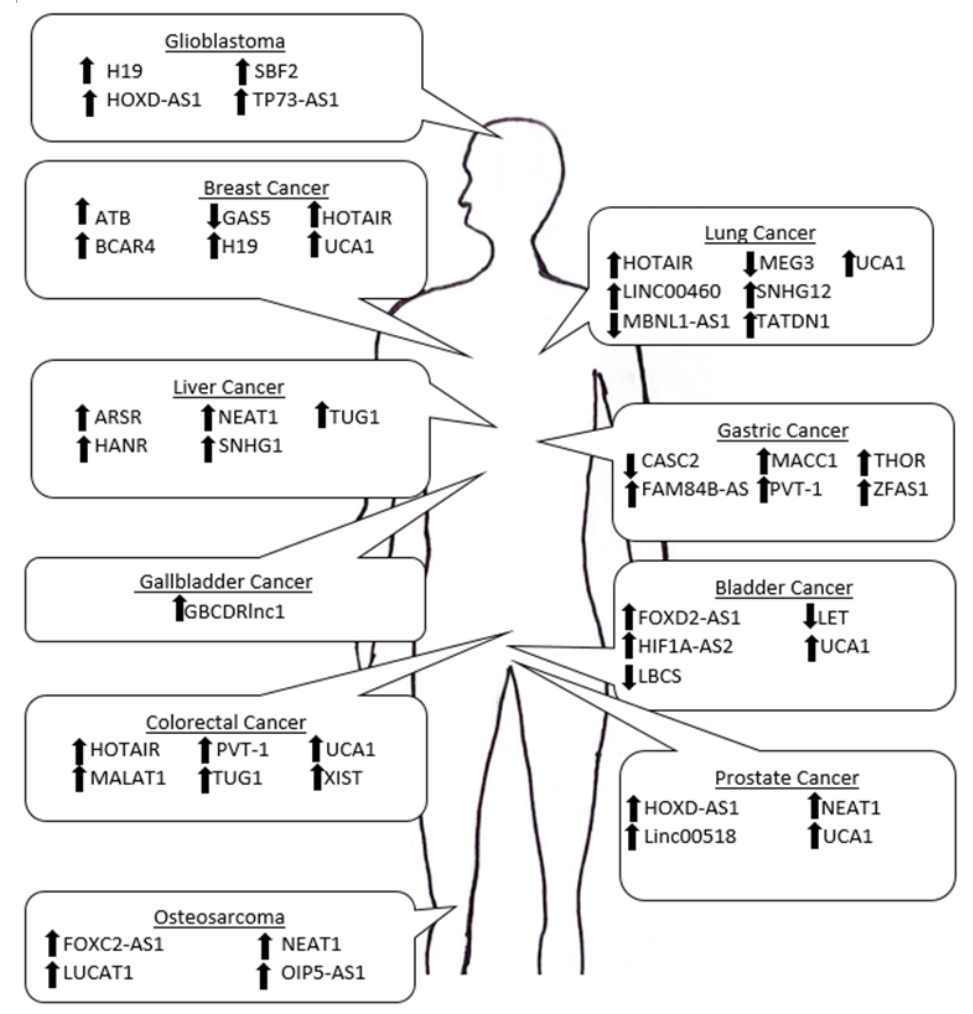

Figure 1. Schematic of the IncRNAs that contribute to therapeutic resistance in a variety of malignancies. The arrows represents the direction of dysregulation when cancer is in a therapeutic resistant state

phosphorylation of ERBB2 and ERBB3 resulting in activation of AKT and kinase $1 / 2^{[15]}$. Another lncRNAHOTAIR, has been reported to be enhanced in breast cancer tumors and also decreases breast cancer cells sensitivity to tamoxifen. HOTAIR mediates tamoxifen resistance by binding directly to ER leading to the activation of downstream genes GREB1, TFF1, and c-Myc ${ }^{[26]}$. LncRNA-UCA1 was also recently discovered to cause tamoxifen resistance of breast cancer lines MCF7 and T47D through activation of the Wnt/ $\beta$-Catenin pathway ${ }^{[116]}$. While others have demonstrated that tamoxifen resistant breast cancer lines LCC2 and LCC9 has elevated levels of UCA1, the tamoxifen resistance is caused by induction of $\mathrm{p}-\mathrm{AKT} / \mathrm{m}-\mathrm{TOR}$ pathway $^{[56]}$.

In non-castration resistant prostate cancer, patients receive androgen therapy, bicalutamide. Bicalutamide are anti-androgen agents that prevents androgen-androgen receptor binding. A common cause of resistance to bicalutamide is development of mutations within the androgen receptor thus preventing bicalutamide sensitivity ${ }^{[110]}$. As cited before prostate cancer tissue of higher grades have elevated levels of lncRNAHOXD-AS1 compared to lower tumor grades. The knockdown of HOXD-AS1 caused prostate cancer cells to become more sensitive to bicalutamide. HOXD-AS1 is able to impact bicalutamide sensitivity by binding to WDR5 and regulating several important signaling pathways ${ }^{[30]}$.

\section{CONCLUSION}

Through the use of transcriptomic analysis such as RNA sequencing, it was found that approximately $75 \%$ of the human genome is transcribed ${ }^{[116]} .2 \%$ of the RNA are then translated into protein, resulting in a majority of RNAs lacking protein capacity ${ }^{[117]}$. A majority of ncRNAs are lncRNAs, with a proportion of lncRNAs having a role in regulating cancer progression ${ }^{[9]}$. LncRNAs perturb cancer development through different facets. IncRNAs HOTAIR and MALAT1 enhance metastatic phenotypes in breast and lung 
cancer, while lncRNA MEG3 and MKLN1-AS1 are downregulated in colorectal cancer and both function as regulators of proliferation ${ }^{[118-121]}$. LncRNAs can also contribute to relapse or refractory disease through their regulation on mechanisms of therapeutic resistance.

For many malignancies, small molecule therapeutic treatments are the predominant course of therapy ${ }^{[122]}$. The development of therapeutic resistance in multiple malignancies leads to a critical need for new therapeutic strategies. The review provides an overview of dysregulated expression of critical lncRNAs and their mechanism of action driving therapeutic resistance and bringing insight to the importance of targeting this type of ncRNA to potentially increase therapeutic efficacy [Figure 1]. LncRNAs such as NEAT1, UCA1, and PVT-1 have been shown to regulate drug resistance in multiple cancer types through different molecular mechanisms. Through understanding how lncRNAs contribute to therapeutic resistance across different malignancies and therapeutic agents, it emphasizes the necessity of additional research into lncRNAs as therapeutic targets and in turn circumvent therapeutic resistance in a more expansive manner.

\section{DECLARATIONS}

\section{Authors' contributions}

Concept: Tsang S, Patel T, Yustein JT

Design: Tsang S, Yustein JT

Wrote (first draft): Tsang $S$

Reviewed, edited and revised: Tsang S, Patel T, Yustein JT

\section{Availability of data and materials}

Not applicable.

\section{Financial support and sponsorship}

This work was supported by Baylor College of Medicine Comprehensive Cancer Training Program (CPRIT RP160283).

\section{Conflicts of interest}

All authors declared that there are no conflicts of interest.

\section{Ethical approval and consent to participate}

Not applicable.

\section{Consent for publication}

Not applicable.

\section{Copyright}

(c) The Author(s) 2019.

\section{REFERENCES}

1. DeVita VT Jr, Chu E. A history of cancer chemotherapy. Cancer Res 2008;68:8643-53.

2. Shewach DS, Kuchta RD. Introduction to cancer chemotherapeutics. Chem Rev 2009;109:2859-61.

3. Dasari S, Tchounwou PB. Cisplatin in cancer therapy: molecular mechanisms of action. Eur J Pharmacol 2014;740:364-78.

4. Keating GM, Santoro A. Sorafenib: a review of its use in advanced hepatocellular carcinoma. Drugs 2009;69:223-40.

5. Hagner N, Joerger M. Cancer chemotherapy: targeting folic acid synthesis. Cancer Manag Res 2010;2:293-301.

6. Caitriona H, Sandra Van S, Daniel BL, Patrick GJ. Cancer drug resistance: an evolving paradigm. Nat Rev Cancer 2013;13:714.

7. Gloss BS, Dinger ME. Realizing the significance of noncoding functionality in clinical genomics. Exp Mol Med 2018;50:97. 
8. Yamada A, Yu P, Lin W, Okugawa Y, Boland CR, et al. A RNA-sequencing approach for the identification of novel long non-coding RNA biomarkers in colorectal cancer. Sci Rep 2018;8:575.

9. Huarte M. The emerging role of IncRNAs in cancer. Nat Med 2015;21:1253-61.

10. Quinn JJ, Chang HY. Unique features of long non-coding RNA biogenesis and function. Nat Rev Genet 2016;17:47-62.

11. Zhang Y, Yang L, Chen LL. Life without A tail: new formats of long noncoding RNAs. Int J Biochem Cell Biol 2014;54:338-49.

12. Ransohoff JD, Wei Y, Khavari PA. The functions and unique features of long intergenic non-coding RNA. Nat Rev Mol Cell Biol 2018;19:143-57.

13. Li Y, Ye Y, Feng B, Qi Y. Long noncoding RNA lncARSR promotes doxorubicin resistance in hepatocellular carcinoma via modulating PTEN-PI3K/Akt pathway. J Cell Biochem 2017;118:4498-507.

14. Shi SJ, Wang LJ, Yu B, Li YH, Jin Y, et al. LncRNA-ATB promotes trastuzumab resistance and invasion-metastasis cascade in breast cancer. Oncotarget 2015;6:11652-63.

15. Godinho MF, Wulfkuhle JD, Look MP, Sieuwerts AM, Sleijfer S, et al. BCAR4 induces antioestrogen resistance but sensitises breast cancer to lapatinib. Br J Cancer 2012;107:947-55.

16. Li Y, Lv S, Ning H, Li K, Zhou X, et al. Down-regulation of CASC2 contributes to cisplatin resistance in gastric cancer by sponging miR-19a. Biomed Pharmacother 2018;108:1775-82.

17. Zhang Y, Li Q, Yu S, Zhu C, Zhang Z, et al. Long non-coding RNA FAM84B-AS promotes resistance of gastric cancer to platinum drugs through inhibition of FAM84B expression. Biochem Biophys Res Commun 2019;509:753-62.

18. Zhang CL, Zhu KP, Ma XL. Antisense lncRNA FOXC2-AS1 promotes doxorubicin resistance in osteosarcoma by increasing the expression of FOXC2. Cancer Lett 2017;396:66-75.

19. An Q, Zhou L, Xu N. Long noncoding RNA FOXD2-AS1 accelerates the gemcitabine-resistance of bladder cancer by sponging miR143. Biomed Pharmacother 2018;103:415-20.

20. Li W, Zhai L, Wang H, Liu C, Zhang J, et al. Downregulation of LncRNA GAS5 causes trastuzumab resistance in breast cancer. Oncotarget 2016;7:27778-86.

21. Cai Q, Wang S, Jin L, Weng M, Zhou D, et al. Long non-coding RNA GBCDRlncl induces chemoresistance of gallbladder cancer cells by activating autophagy. Mol Cancer 2019;18:82.

22. Han J, Han B, Wu X, Hao J, Dong X, et al. Knockdown of IncRNA H19 restores chemo-sensitivity in paclitaxel-resistant triplenegative breast cancer through triggering apoptosis and regulating Akt signaling pathway. Toxicol Appl Pharmacol 2018;359:55-61.

23. Jia L, Tian Y, Chen Y, Zhang G. The silencing of LncRNA-H19 decreases chemoresistance of human glioma cells to temozolomide by suppressing epithelial-mesenchymal transition via the Wnt/beta-Catenin pathway. Onco Targets Ther 2018;11:313-21.

24. Xiao J, Lv Y, Jin F, Liu Y, Ma Y, et al. LncRNA HANR promotes tumorigenesis and increase of chemoresistance in hepatocellular carcinoma. Cell Physiol Biochem 2017;43:1926-38.

25. Chen X, Liu M, Meng F, Sun B, Jin X, et al. The long noncoding RNA HIF1A-AS2 facilitates cisplatin resistance in bladder cancer. J Cell Biochem 2019;120:243-52.

26. Xue X, Yang YA, Zhang A, Fong KW, Kim J, et al. LncRNA HOTAIR enhances ER signaling and confers tamoxifen resistance in breast cancer. Oncogene 2016;35:2746-55.

27. Xiao Z, Qu Z, Chen Z, Fang Z, Zhou K, et al. LncRNA HOTAIR is a prognostic biomarker for the proliferation and chemoresistance of colorectal cancer via MiR-203a-3p-mediated Wnt/ss-catenin signaling pathway. Cell Physiol Biochem 2018;46:1275-85.

28. Yang Y, Jiang C, Yang Y, Guo L, Huang J, et al. Silencing of LncRNA-HOTAIR decreases drug resistance of non-small cell lung cancer cells by inactivating autophagy via suppressing the phosphorylation of ULK1. Biochem Biophys Res Commun 2018;497:1003-10.

29. Zhou H, Ma Y, Zhong D, Yang L. Knockdown of IncRNA HOXD-AS1 suppresses proliferation, migration and invasion and enhances cisplatin sensitivity of glioma cells by sponging miR-204. Biomed Pharmacother 2019;112:108633.

30. Gu P, Chen X, Xie R, Han J, Xie W, et al. IncRNA HOXD-AS1 regulates proliferation and chemo-resistance of castration-resistant prostate cancer via recruiting WDR5. Mol Ther 2017;25:1959-73.

31. Chen X, Xie R, Gu P, Huang M, Han J, et al. Long Noncoding RNA LBCS inhibits self-renewal and chemoresistance of bladder cancer stem cells through epigenetic silencing of SOX2. Clin Cancer Res 2019;25:1389-403.

32. Zhuang J, Shen L, Yang L, Huang X, Lu Q, et al. TGFbetal promotes gemcitabine resistance through regulating the LncRNA-LET/ NF90/miR-145 signaling axis in bladder cancer. Theranostics 2017;7:3053-67.

33. Ma G, Zhu J, Liu F, Yang Y. Long noncoding RNA LINC00460 promotes the gefitinib resistance of nonsmall cell lung cancer through epidermal growth factor receptor by sponging miR-769-5p. DNA Cell Biol 2019;38:176-83.

34. He J, Sun M, Geng H, Tian S. Long non-coding RNA Linc00518 promotes paclitaxel resistance of the human prostate cancer by sequestering miR-216b-5p. Biol Cell 2019;111:39-50.

35. Han Z, Shi L. Long non-coding RNA LUCAT1 modulates methotrexate resistance in osteosarcoma via miR-200c/ABCB1 axis. Biochem Biophys Res Commun 2018;495:947-53.

36. He W, Liang B, Wang C, Li S, Zhao Y, et al. MSC-regulated lncRNA MACC1-AS1 promotes stemness and chemoresistance through fatty acid oxidation in gastric cancer. Oncogene 2019;38:4637-54.

37. Li P, Zhang X, Wang H, Wang L, Liu T, et al. MALAT1 is associated with poor response to oxaliplatin-based chemotherapy in colorectal cancer patients and promotes chemoresistance through EZH2. Mol Cancer Ther 2017;16:739-51.

38. Li P, Xing W, Xu J, Yuan D, Liang G, et al. microRNA-301b-3p downregulation underlies a novel inhibitory role of long non-coding RNA MBNL1-AS1 in non-small cell lung cancer. Stem Cell Res Ther 2019;10:144.

39. Liu J, Wan L, Lu K, Sun M, Pan X, et al. The long noncoding RNA MEG3 contributes to cisplatin resistance of human lung 
adenocarcinoma. PLoS One 2015;10:e0114586.

40. Chen S, Xia X. Long noncoding RNA NEAT1 suppresses sorafenib sensitivity of hepatocellular carcinoma cells via regulating miR335-c-Met. J Cell Physiol 2019; doi: 10.1002/jcp.27567.

41. Hu Y, Yang Q, Wang L, Wang S, Sun F, et al. Knockdown of the oncogene lncRNA NEAT1 restores the availability of miR-34c and improves the sensitivity to cisplatin in osteosarcoma. Biosci Rep 2018;38.

42. Tian X, Zhang G, Zhao H, Li Y, Zhu C. Long non-coding RNA NEAT1 contributes to docetaxel resistance of prostate cancer through inducing RET expression by sponging miR-34a. RSC Advances 2017;7:42986-96.

43. Song L, Zhou Z, Gan Y, Li P, Xu Y, et al. Long noncoding RNA OIP5-AS1 causes cisplatin resistance in osteosarcoma through inducing the LPAATbeta/PI3K/AKT/mTOR signaling pathway by sponging the miR-340-5p. J Cell Biochem 2019;120:9656-66.

44. Fan H, Zhu JH, Yao XQ. Knockdown of long noncoding RNA PVT1 reverses multidrug resistance in colorectal cancer cells. Mol Med Rep 2018;17:8309-15.

45. Ping G, Xiong W, Zhang L, Li Y, Zhang Y, et al. Silencing long noncoding RNA PVT1 inhibits tumorigenesis and cisplatin resistance of colorectal cancer. Am J Transl Res 2018;10:138-49.

46. Du P, Hu C, Qin Y, Zhao J, Patel R, et al. LncRNA PVT1 mediates antiapoptosis and 5-fluorouracil resistance via increasing Bcl2 expression in gastric cancer. J Oncol 2019;2019:10.

47. Zhang Z, Yin J, Lu C, Wei Y, Zeng A, et al. Exosomal transfer of long non-coding RNA SBF2-AS1 enhances chemoresistance to temozolomide in glioblastoma. J Exp Clin Cancer Res 2019;38:166.

48. Li W, Dong X, He C, Tan G, Li Z, et al. LncRNA SNHG1 contributes to sorafenib resistance by activating the Akt pathway and is positively regulated by miR-21 in hepatocellular carcinoma cells. J Exp Clin Cancer Res 2019;38:183.

49. Wang P, Chen D, Ma H, Li Y. LncRNA SNHG12 contributes to multidrug resistance through activating the MAPK/Slug pathway by sponging miR-181a in non-small cell lung cancer. Oncotarget 2017;8:84086-101.

50. Wang L, Shang X, Feng Q. LncRNA TATDN1 contributes to the cisplatin resistance of non-small cell lung cancer through TATDN1/ miR-451/TRIM66 axis. Cancer Biol Ther 2019;20:261-71.

51. Song H, Xu Y, Shi L, Xu T, Fan R, et al. LncRNA THOR increases the stemness of gastric cancer cells via enhancing SOX9 mRNA stability. Biomed Pharmacother 2018;108:338-46.

52. Mazor G, Levin L, Picard D, Ahmadov U, Caren H, et al. The lncRNA TP73-AS1 is linked to aggressiveness in glioblastoma and promotes temozolomide resistance in glioblastoma cancer stem cells. Cell Death Dis 2019;10:246.

53. Li C, Gao Y, Li Y, Ding D. TUG1 mediates methotrexate resistance in colorectal cancer via miR-186/CPEB2 axis. Biochem Biophys Res Commun 2017;491:552-7.

54. Yang LT, Du Y, Yu PF, Fan J, Wang XB, et al. Long non-coding RNA TUG1 regulates the development of multidrug resistance in hepatocellular carcinoma via P-gp and MDR1. Int J Clin Exp Med 2016;9:21388-96.

55. Fan Y, Shen B, Tan M, Mu X, Qin Y, et al. Long non-coding RNA UCA1 increases chemoresistance of bladder cancer cells by regulating Wnt signaling. Febs J 2014;281:1750-8.

56. Wu C, Luo J. Long non-coding RNA (IncRNA) urothelial carcinoma-associated 1 (UCA1) enhances tamoxifen resistance in breast cancer cells via inhibiting mTOR signaling pathway. Med Sci Monit 2016;22:3860-7.

57. Bian Z, Jin L, Zhang J, Yin Y, Quan C, et al. LncRNA-UCA1 enhances cell proliferation and 5-fluorouracil resistance in colorectal cancer by inhibiting miR-204-5p. Sci Rep 2016;6:23892.

58. Cheng N, Cai W, Ren S, Li X, Wang Q, et al. Long non-coding RNA UCA1 induces non-T790M acquired resistance to EGFR-TKIs by activating the AKT/mTOR pathway in EGFR-mutant non-small cell lung cancer. Oncotarget 2015;6:23582-93.

59. Wang X, Yang B, Ma B. The UCA1/miR-204/Sirt1 axis modulates docetaxel sensitivity of prostate cancer cells. Cancer Chemother Pharmacol 2016;78:1025-31.

60. Zhu J, Zhang R, Yang D, Li J, Yan X, et al. Knockdown of long non-coding RNA XIST inhibited doxorubicin resistance in colorectal cancer by upregulation of miR-124 and downregulation of SGK1. Cell Physiol Biochem 2018;51:113-28.

61. Xu W, He L, Li Y, Tan Y, Zhang F, et al. Silencing of lncRNA ZFAS1 inhibits malignancies by blocking Wnt/beta-catenin signaling in gastric cancer cells. Biosci Biotechnol Biochem 2018;82:456-65.

62. Schirrmacher V. From chemotherapy to biological therapy: a review of novel concepts to reduce the side effects of systemic cancer treatment (Review). Int J Oncol 2019;54:407-19.

63. Allen KE, Weiss GJ. Resistance may not be futile: microRNA biomarkers for chemoresistance and potential therapeutics. Mol Cancer Ther 2010;9:3126-36.

64. Ralhan R, Kaur J. Alkylating agents and cancer therapy. Expert Opin Ther Pat 2007;17:1061-75.

65. Lee CY. Strategies of temozolomide in future glioblastoma treatment. Onco Targets Ther 2017;10:265-70.

66. Chen X, Wu Y, Dong H, Zhang CY, Zhang Y. Platinum-based agents for individualized cancer treatment. Curr Mol Med 2013;13:1603-12.

67. Matsuda A, Yamaoka K, Tango T. Quality of life in advanced non-small cell lung cancer patients receiving palliative chemotherapy: a meta-analysis of randomized controlled trials. Exp Ther Med 2012;3:134-40.

68. Morgensztern D, Ng SH, Gao F, Govindan R. Trends in stage distribution for patients with non-small cell lung cancer: a national cancer database survey. J Thorac Oncol 2010;5:29-33.

69. Kamat AM, Hahn NM, Efstathiou JA, Lerner SP, Malmstrom PU, et al. Bladder cancer. Lancet 2016;388:2796-810.

70. Kurtova AV, Xiao J, Mo Q, Pazhanisamy S, Krasnow R, et al. Blocking PGE2-induced tumour repopulation abrogates bladder cancer chemoresistance. Nature 2015;517:209-13.

71. Luo J, Chen J, Li H, Yang Y, Yun H, et al. LncRNA UCA1 promotes the invasion and EMT of bladder cancer cells by regulating the 
miR-143/HMGB1 pathway. Oncol Lett 2017;14:5556-62.

72. Wang H, Guan Z, He K, Qian J, Cao J, et al. LncRNA UCA1 in anti-cancer drug resistance. Oncotarget 2017;8:64638-50.

73. Sastre J, Garcia-Saenz JA, Diaz-Rubio E. Chemotherapy for gastric cancer. World J Gastroenterol 2006;12:204-13.

74. Oba K, Paoletti X, Bang YJ, Bleiberg H, Burzykowski T, et al. Role of chemotherapy for advanced/recurrent gastric cancer: an individual-patient-data meta-analysis. Eur J Cancer 2013;49:1565-77.

75. Wong N, Gu Y, Kapoor A, Lin X, Ojo D, et al. Upregulation of FAM84B during prostate cancer progression. Oncotarget 2017;8:19218-35.

76. Alcindor T, Beauger N. Oxaliplatin: a review in the era of molecularly targeted therapy. Curr Oncol 2011;18:18-25.

77. Houthuijzen JM, Daenen LG, Roodhart JM, Voest EE. The role of mesenchymal stem cells in anti-cancer drug resistance and tumour progression. Br J Cancer 2012;106:1901-6.

78. Roodhart JM, Daenen LG, Stigter EC, Prins HJ, Gerrits J, et al. Mesenchymal stem cells induce resistance to chemotherapy through the release of platinum-induced fatty acids. Cancer Cell 2011;20:370-83.

79. Wang T, Fahrmann JF, Lee H, Li YJ, Tripathi SC, et al. JAK/STAT3-regulated fatty acid beta-oxidation is critical for breast cancer stem cell self-renewal and chemoresistance. Cell Metab 2018;27:1357.

80. Rowinsky EK. The development and clinical utility of the taxane class of antimicrotubule chemotherapy agents. Annu Rev Med 1997;48:353-74.

81. Yao H, He G, Yan S, Chen C, Song L, et al. Triple-negative breast cancer: is there a treatment on the horizon? Oncotarget 2017;8:1913-24.

82. Ivery MT, Le T. Modeling the interaction of paclitaxel with beta-tubulin. Oncol Res 2003;14:1-19.

83. Raveh E, Matouk IJ, Gilon M, Hochberg A. The H19 Long non-coding RNA in cancer initiation, progression and metastasis - a proposed unifying theory. Mol Cancer 2015;14:184.

84. Attard G, Parker C, Eeles RA, Schroder F, Tomlins SA, et al. Prostate cancer. Lancet 2016;387:70-82.

85. Chakravarty D, Sboner A, Nair SS, Giannopoulou E, Li R, et al. The oestrogen receptor alpha-regulated lncRNA NEAT1 is a critical modulator of prostate cancer. Nat Commun 2014;5:5383.

86. Naganuma T, Hirose T. Paraspeckle formation during the biogenesis of long non-coding RNAs. RNA Biol 2013;10:456-61.

87. Thorn CF, Oshiro C, Marsh S, Hernandez-Boussard T, McLeod H, et al. Doxorubicin pathways: pharmacodynamics and adverse effects. Pharmacogenet Genomics 2011;21:440-6.

88. Misra S, Chaturvedi A, Misra NC, Sharma ID. Carcinoma of the gallbladder. Lancet Oncol 2003;4:167-76.

89. Kresl JJ, Schild SE, Henning GT, Gunderson LL, Donohue J, et al. Adjuvant external beam radiation therapy with concurrent chemotherapy in the management of gallbladder carcinoma. Int J Radiat Oncol Biol Phys 2002;52:167-75.

90. Pei G, Luo M, Ni X, Wu J, Wang S, et al. Autophagy facilitates metadherin-induced chemotherapy resistance through the AMPK/ ATG5 pathway in gastric cancer. Cell Physiol Biochem 2018;46:847-59.

91. Arencibia JM, Pastor-Flores D, Bauer AF, Schulze JO, Biondi RM. AGC protein kinases: from structural mechanism of regulation to allosteric drug development for the treatment of human diseases. Biochim Biophys Acta 2013;1834:1302-21.

92. Tanaka S, Arii S. Molecular targeted therapy for hepatocellular carcinoma in the current and potential next strategies. J Gastroenterol 2011;46:289-96.

93. Sano H, Leboeuf JP, Novitskiy SV, Seo S, Zaja-Milatovic S, et al. The Foxc2 transcription factor regulates tumor angiogenesis. Biochem Biophys Res Commun 2010;392:201-6.

94. Plunkett W, Huang P, Xu YZ, Heinemann V, Grunewald R, et al. Gemcitabine: metabolism, mechanisms of action, and selfpotentiation. Semin Oncol 1995;22:3-10.

95. Liu X, Yao D, Liu C, Cao Y, Yang Q, et al. Overexpression of ABCC3 promotes cell proliferation, drug resistance, and aerobic glycolysis and is associated with poor prognosis in urinary bladder cancer patients. Tumour Biol 2016;37:8367-74.

96. Sara JD, Kaur J, Khodadadi R, Rehman M, Lobo R, et al. 5-fluorouracil and cardiotoxicity: a review. Ther Adv Med Oncol 2018; doi: $10.1177 / 1758835919871363$.

97. Miura K, Kinouchi M, Ishida K, Fujibuchi W, Naitoh T, et al. 5-fu metabolism in cancer and orally-administrable 5-fu drugs. Cancers 2010;2:1717-30.

98. Carter SK, Comis RL. Gastric cancer: current status of treatment. J Natl Cancer Inst 1977;58:567-78.

99. Wilhelm S, Carter C, Lynch M, Lowinger T, Dumas J, et al. Discovery and development of sorafenib: a multikinase inhibitor for treating cancer. Nat Rev Drug Discov 2006;5:835-44.

100. Guo S, Chen W, Luo Y, Ren F, Zhong T, et al. Clinical implication of long non-coding RNA NEAT1 expression in hepatocellular carcinoma patients. Int J Clin Exp Pathol 2015;8:5395-402.

101. Padma VV. An overview of targeted cancer therapy. Biomedicine (Taipei) 2015;5:19.

102. Guo F, Cao Z, Guo H, Li S. The action mechanism of lncRNA-HOTAIR on the drug resistance of non-small cell lung cancer by regulating Wnt signaling pathway. Exp Ther Med 2018;15:4885-9.

103. Giaccone G. The role of gefitinib in lung cancer treatment. Clin Cancer Res 2004;10:4233s-7s.

104. Arteaga CL. Trastuzumab, an appropriate first-line single-agent therapy for HER2-overexpressing metastatic breast cancer. Breast Cancer Res 2003;5:96-100.

105. Gajria D, Chandarlapaty S. HER2-amplified breast cancer: mechanisms of trastuzumab resistance and novel targeted therapies. Expert Rev Anticancer Ther 2011;11:263-75.

106. Montemurro F, Donadio M, Clavarezza M, Redana S, Jacomuzzi ME, et al. Outcome of patients with HER2-positive advanced breast cancer progressing during trastuzumab-based therapy. Oncologist 2006;11:318-24.

107. Niedersuss-Beke D, Puntus T, Kunit T, Grunberger B, Lamche M, et al. Neoadjuvant chemotherapy with gemcitabine plus cisplatin in 
patients with locally advanced bladder cancer. Oncology 2017;93:36-42.

108. Nishio M, Kim DW, Wu YL, Nakagawa K, Solomon BJ, et al. Crizotinib versus chemotherapy in Asian patients with ALK-positive advanced non-small cell lung cancer. Cancer Res Treat 2018;50:691-700.

109. Camidge DR, Otterson GA, Clark JW, Ou SHI, Weiss J, et al. Crizotinib in patients (pts) with MET-amplified non-small cell lung cancer (NSCLC): updated safety and efficacy findings from a phase 1 trial. J Clin Oncol 2018;36:9062.

110. Rau KM, Kang HY, Cha TL, Miller SA, Hung MC. The mechanisms and managements of hormone-therapy resistance in breast and prostate cancers. Endocr Relat Cancer 2005;12:511-32.

111. Fan C, Oh DS, Wessels L, Weigelt B, Nuyten DS, et al. Concordance among gene-expression-based predictors for breast cancer. $\mathrm{N}$ Engl J Med 2006;355:560-9.

112. Harbeck N, Gnant M. Breast cancer. Lancet 2017;389:1134-50.

113. Tremont A, Lu J, Cole JT. Endocrine therapy for early breast cancer: updated review. Ochsner J 2017;17:405-11.

114. Sporn MB LS. Agents for chemoprevention and their mechanism of action. Holland-Frei Cancer Medicine: BC Decker; 2003.

115. Godinho MF, Sieuwerts AM, Look MP, Meijer D, Foekens JA, et al. Relevance of BCAR4 in tamoxifen resistance and tumour aggressiveness of human breast cancer. Br J Cancer 2010;103:1284-91.

116. Liu H, Wang G, Yang L, Qu J, Yang Z, et al. Knockdown of long non-coding RNA UCA1 increases the tamoxifen sensitivity of breast cancer cells through inhibition of Wnt/beta-catenin pathway. PLoS One 2016;11:e0168406.

117. Feng Y, Hu X, Zhang Y, Zhang D, Li C, et al. Methods for the study of long noncoding RNA in cancer cell signaling. Methods Mol Biol 2014;1165:115-43.

118. Arun G, Diermeier S, Akerman M, Chang KC, Wilkinson JE, et al. Differentiation of mammary tumors and reduction in metastasis upon Malat1 lncRNA loss. Genes Dev 2016;30:34-51.

119. Gutschner T, Hammerle M, Eissmann M, Hsu J, Kim Y, et al. The noncoding RNA MALAT1 is a critical regulator of the metastasis phenotype of lung cancer cells. Cancer Res 2013;73:1180-9.

120. Yin DD, Liu ZJ, Zhang E, Kong R, Zhang ZH, et al. Decreased expression of long noncoding RNA MEG3 affects cell proliferation and predicts a poor prognosis in patients with colorectal cancer. Tumour Biol 2015;36:4851-9.

121. Marin-Bejar O, Marchese FP, Athie A, Sanchez Y, Gonzalez J, et al. Pint lincRNA connects the p53 pathway with epigenetic silencing by the Polycomb repressive complex 2. Genome Biol 2013;14:R104.

122. Hoelder S, Clarke PA, Workman P. Discovery of small molecule cancer drugs: successes, challenges and opportunities. Mol Oncol 2012;6:155-76. 